\title{
Pengembangan Metode Quad Smoothness Reduced Difference Expansion Untuk Steganography Pada Audio
}

\author{
Danang Adi Nugroho, Tohari Ahmad, dan Henning Titi Ciptaningtyas \\ DepatemenTeknik Informatika, Fakultas Teknologi Informasi, Institut Teknologi Sepuluh Nopember \\ (ITS) \\ e-mail: danang13@mhs.if.its.ac.id
}

\begin{abstract}
Abstrak-Steganography adalah salah satu bagian dari teknik penyembunyian data. Tujuan utama dari steganography adalah untuk menjaga orang lain agar tidak mengetahui informasi rahasia yang disembunyikan. Banyak penelitian yang telah dilakukan dalam bidang ini, khususnya steganography dengan media citra digital. Pada penelitian ini akan dilakukan penyembunyian data pada audio. Berkas audio yang akan digunakan adalah berkas audio dengan format WAV. Berkas audio tersebut memiliki panjang sampel 8-bit dan merupakan berkas audio mono atau single channel. Data yang disembunyikan pada audio merupakan berkas pesan tersembunyi berbentuk teks. Metode-metode yang diimplementasikan untuk penyembunyian data pada audio adalah general reduced difference expansion, quad-based general rde, block overlap general rde, dan quad smoothness general rde. Perangkat lunak yang digunakan untuk melakukan penyembunyian data diimplementasikan dengan menggunakan bahasa pemrograman Python versi 3.6.0 dan Anaconda. Pengujian dilakukan pada empat buah berkas audio berbeda. Berkas audio yang digunakan merupakan potongan dari sebuah lagu dengan panjang 94 detik. Uji coba dilakukan dengan menyisipkan pesan tersembunyi berupa teks dengan ukuran-ukuran yang berbeda. Dari hasil analisa uji coba didapatkan bahwa pemilihan coveraudio berpengaruh pada nilai PSNR stegoaudio. Panjang coveraudio tidak berpengaruh pada kapasitas penyisipan pesan tersembunyi. GRDE dan Quad-RDE memiliki kapasitas penyimpanan lebih besar dari metode lainnya. Metode RDE adalah metode yang memiliki hasil PSNR yang lebih besar dari metode lainnya.
\end{abstract}

Kata Kunci-Steganography, difference expansion, reduced difference expansion, generalized difference expansion.

\section{PENDAHULUAN}

$\mathrm{S}_{\mathrm{p}}^{\mathrm{T}}$ TEGANOGRAPHY adalah salah satu bagian dari teknik penyembunyian data [1]. Sebuah informasi rahasia dikodekan sedemikian rupa sehingga keberadaan informasi tersebut tidak diketahui. Tujuan utama steganography adalah untuk menjaga orang lain agar tidak mengetahui keberadaan informasi rahasia tersebut [2].

Banyak penelitian telah dilakukan dalam bidang ini, khususnya steganography dengan media citra digital. Salah satu metode yang terkenal adalah difference expansion oleh Tian [3]. Tian menyebut metodenya juga dapat diaplikasikan pada audio dan video digital.

Pada penelitian ini akan dilakukan penyembunyian data menggunakan metode yang diusulkan oleh Holil [4], yaitu: general reduced difference expansion, quad-based general rde, block overlap general rde, dan quad smoothness general rde. Metode-metode tersebut akan diaplikasikan pada audio. Diharapkan dengan pengaplikasian metode-metode tersebut dapat menambah metode pengaplikasian steganography pada audio dan menumbuhkan semangat untuk penelitian selanjutnya.

Dikemudian hari penyembunyian data dapat diaplikasikan pada media yang lebih beragam. Komunikasi data akan semakin aman.

\section{PENELITIAN TERKAIT}

Metode difference expansion dan metode pengembanganpengembangannya telah banyak diteliti pada citra digital [3]. Penelitian ini mengacu pada literatur jurnal T. Ahmad dan M. Holil yang berjudul "Increasing the Performance of Difference Expansion-based Steganography when Securing Medical Data". Pada [4] dilakukan pengembangan dari ke tiga metode yang telah disebutkan. Pada penelitian tersebut dihasilkan tiga metode steganography yang juga diterapkan pada citra digital.

\section{SKEMA YANG DIUSULKAN}

\section{A. Desain Umum Perangkat Lunak}

Perangkat lunak yang dirancang untuk penelitian ini adalah perangkat lunak penyisipan pesan tersembunyi pada berkas audio. Perangkat lunak penyisipan pesan terdiri atas dua proses, yaitu proses embedding dan proses extraction. Proses embedding adalah proses penyisipan pesan tersembunyi ke dalam berkas audio. Proses embedding memerlukan data masukan berupa berkas coveraudio dan berkas pesan tersembunyi. Setelah proses embedding selesai maka perangkat lunak akan mengeluarkan berkas stegoaudio dan berkas location map. Proses extraction adalah proses pengembalian pesan tersembunyi dari berkas stegoaudio. Data yang diperlukan proses extraction adalah berkas stegoaudio dan berkas location map. Setelah pesan tersembunyi dikembalikan dari stegoaudio, selanjutnya berkas stegoaudio akan dikembalikan ke bentuk semula (coveraudio). Data 
keluaran dari proses extraction adalah berkas audio yang identik dengan coveraudio dan berkas pesan tersembunyi.

\section{B. Metode Penyisipan}

Perangkat lunak mengaplikasikan enam metode penyisipan data. Metode-metode tersebut adalah difference expansion (DE) [3], reduced difference expansion (RDE), generalized reduced difference expansion (GRDE), quad-based reduced difference expansion (Quad-RDE) [4], block overlap reduced difference expansion (Overlap-RDE) [4], dan quad smoothness reduced difference expansion (Quad-SmoothnessRDE) [4]. Setiap metode memiliki tahapan proses embedding dan proses extraction yang berbeda.

\section{Proses Embedding}

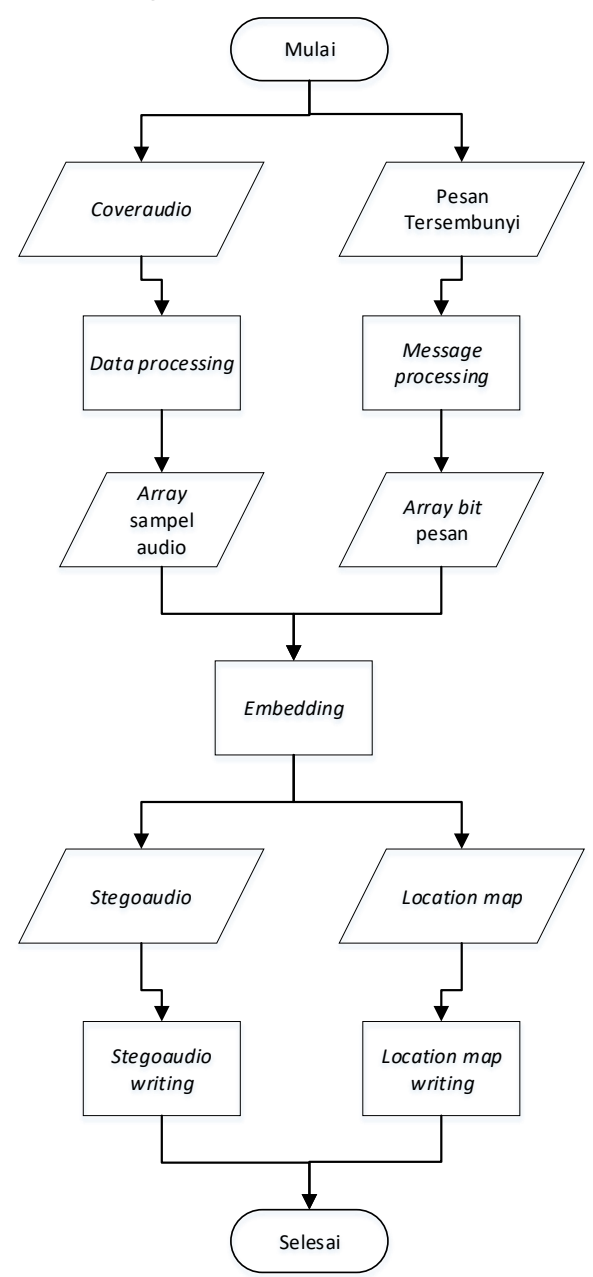

Gambar 1. Diagram alir yang menunjukkan alir proses embedding pada perangkat lunak.

Secara umum proses embedding terdiri dari beberapa tahapan, yaitu: data processing, message processing, embedding, stegoaudio writing, dan location map writing. Tahap data processing dan embedding berbeda untuk setiap metode. Pada tahap data processing dilakukan pemrosesan berkas coveraudio menjadi bentuk array. Array tersebut berisikan sampel-sampel suara pada coveraudio. Bentuk array berbeda untuk setiap metode. Bentuk array dapat dilihat Tabel
1. Pemrosesan pesan tersembunyi dilakukan pada tahap message processing. Pesan tersembunyi diubah menjadi bentuk bit sehingga dapat disisipkan pada coveraudio. Bit-bit tersebut disimpan dalam array satu dimensi. Setelah itu, bit-bit pesan tersembunyi disisipkan pada sampel-sampel coveraudio. Location map dikumpulkan sejalan dengan proses embedding. Setelah proses embedding selesai maka tahap selanjutnya adalah stegoaudio writing, dan location map writing. Sampelsampel coveraudio yang telah diubah akan ditulis menjadi berkas stegoaudio. Location map ditulis menjadi berkas location map. Diagram alir proses embedding dapat dilihat pada Gambar 1.

\section{Proses Extraction}

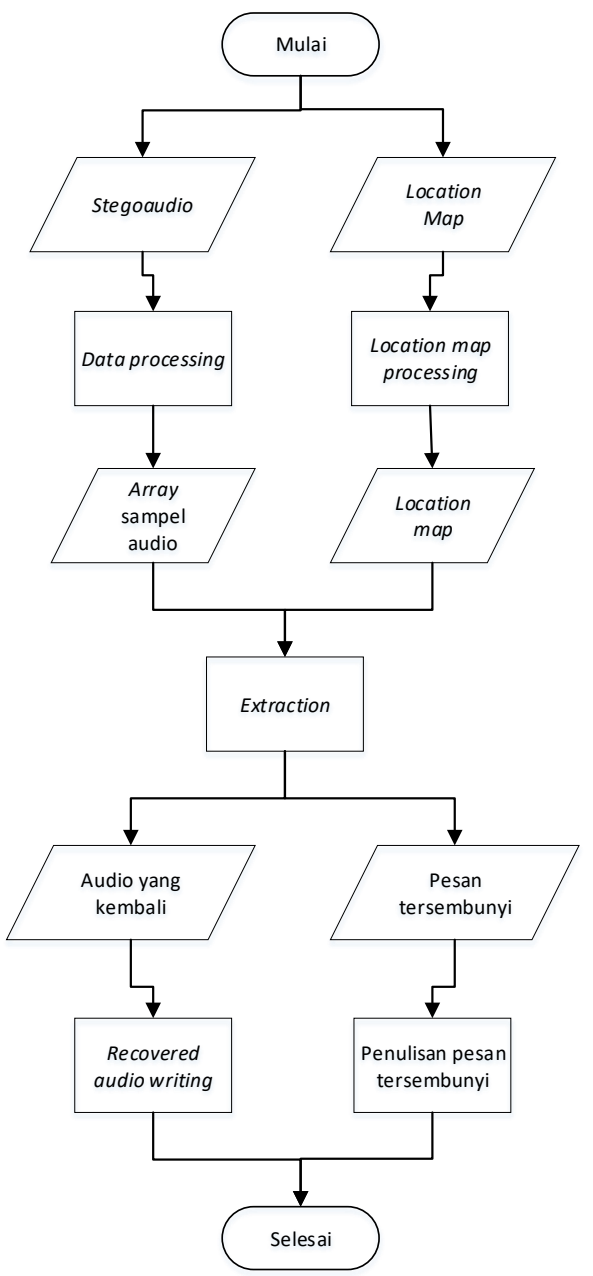

Gambar 2. Diagram alir yang menunjukkan alir proses extraction pada perangkat lunak.

Tahap-tahap proses extraction yaitu: data processing, location map processing, extraction, recovered audio writing, dan penulisan pesan tersembunyi. Pada tahap data processing, stegoaudio diproses menjadi array yang berisikan sampelsampel stegoaudio. Bentuk array juga dapat dilihat pada Tabel 1. Berkas location map diproses dalam tahap location map processing. Location map diperlukan agar stegoaudio dapat dikembalikan seperti semula. Setelah proses extraction selesai, dilakukan penulisan berkas audio yang telah dikembalikan dan penulisan berkas pesan tersembunyi. Masing-masing pada 
tahap recovered audio writing dan tahap penulisan pesan tersembunyi. Diagram alir proses extraction dapat dilihat pada Gambar 2.

Tabel 1.

Bentuk array pada data processing. Array ini digunakan untuk memudahkan proses embedding dan extraction.

\begin{tabular}{cl}
\hline \hline Metode & Bentuk Array \\
\hline DE & $(\mathrm{n}, 2)$ \\
RDE & $(\mathrm{n}, 2)$ \\
GRDE & $(\mathrm{n}, 4)$ \\
Quad-RDE & $(\mathrm{n}, 4)$ \\
Overlap-RDE & $(\mathrm{n}, 1)$ \\
Quad-Smoothness-RDE & $(\mathrm{n}, 4,4)$ \\
\hline
\end{tabular}

\section{E. Antarmuka}

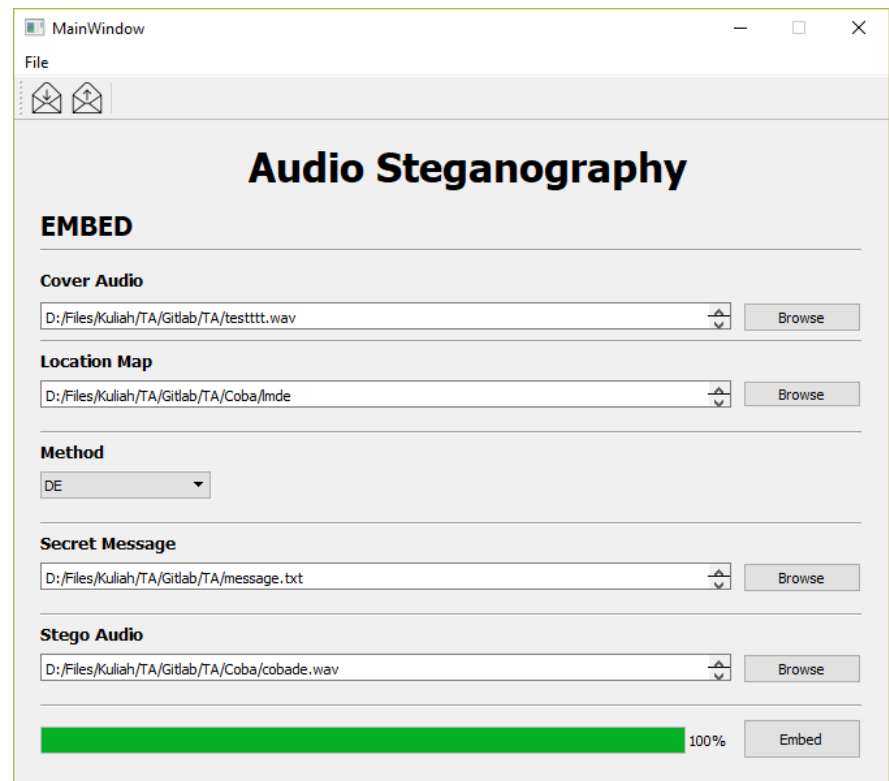

Gambar 3. Antarmuka ui yang merupakan antarmuka utama perangkat lunak yang berisi tombol-tombol yang menghubungkan dengan proses-proses terkait.

Pada penelitian ini dibuat antarmuka untuk perangkat lunak yang dikembangkan. Antarmuka utama dapat dilihat pada Gambar 3. Proses-proses utama perangkat lunak dapat dijalankan pada antarmuka ini.

Setelah penyisipan selesai, akan keluar antarmuka finishdialog yang dapat dilihat pada Gambar 4. Grafik sampel audio dari coveraudio dan stegoaudio dapat dilihat pada antarmuka ini. Pada antarmuka ini dapat juga dilihat hasil perhitungan $P S N R$ yang merupakan nilai beda antar coveraudio dan stegoaudio.

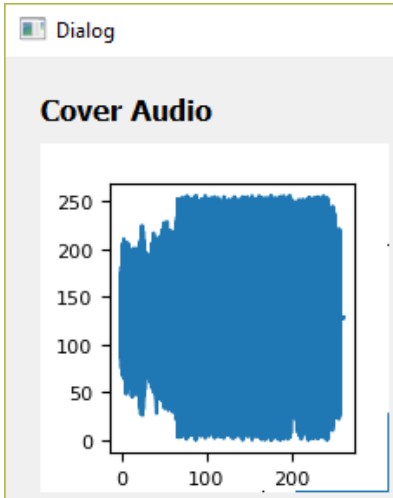

\section{Stego Audio}

PSNR Value: $\quad 61.0701257023$
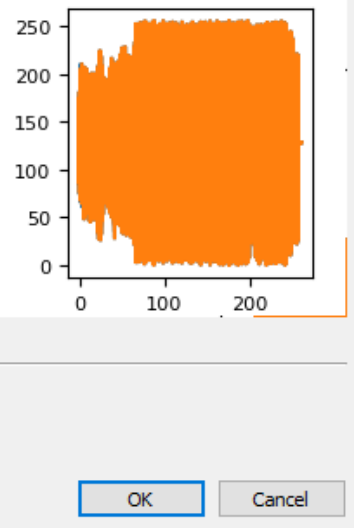

Gambar 4. Antarmuka finishdialog yang menggunakan pustaka matplotlib.pyplot yang digunakan untuk membuat grafik. Terdapat juga nilai psnr antara coveraudio dan stegoaudio

Setelah proses pengambilan data (extraction), akan keluar antarmuka hashform yang dapat dilihat pada Gambar 5. Pada antarmuka ini dapat dihitung nilai hash yang dapat digunakan untuk mencocokkan audio yang telah dikembalikan dengan coveraudio.

\begin{tabular}{|c|c|c|c|}
\hline [1] Form & - & $\square$ & $\times$ \\
\hline \multicolumn{4}{|l|}{ Hash Checker } \\
\hline \multicolumn{4}{|l|}{ Audio 1} \\
\hline D:/Files/Kuliah/TA/Gitlab/TA/Coba/returnde.wav & $\hat{v}$ & Browse & \\
\hline \multicolumn{4}{|l|}{ Audio 2} \\
\hline D:/Files/Kuliah/TA/Gitlab/TA/testttt.wav & $\hat{v}$ & Browse & \\
\hline Check & & & \\
\hline \multicolumn{4}{|l|}{$\begin{array}{l}\text { 79fdb5f2f1d6b6a3441785e 1eb354b } 15 \\
\text { 79fdb5f2f1d6b6a3441785e 1eb354b } 15 \\
\text { Cocok }\end{array}$} \\
\hline
\end{tabular}

Gambar 5. Antarmuka hashform yang menampilkan hasil fungsi hash kedua audio masukan.

\section{F. Data Pengujian}

Data pengujian yang digunakan untuk uji coba perangkat lunak penyisipan pesan tersembunyi adalah berkas audio dengan format wav dan mempunyai kedalaman 8-bit, berkas pesan tersembunyi dengan format txt.

\section{HASIL DAN PEMBAHASAN}

Metode-metode penyembunyian pesan tersembunyi pada berkas audio diuji dengan memperhatikan kualitas stegoaudio dan kapasitas coveraudio. Beberapa skenario uji coba akan 
dilakukan dengan membandingkan PSNR pada berkas-berkas coveraudio dengan ukuran berkas tersembunyi yang berbedabeda. Skenario-skenario uji coba dapat dilihat pada Tabel 2.

Tabel 2.

Skenario-skenario uji coba.

\begin{tabular}{cl}
\hline \hline Skenario & Ukuran Berkas \\
\hline Uji Coba 1 & $25 \mathrm{~kb}$ \\
Uji Coba 2 & $50 \mathrm{~kb}$ \\
Uji Coba 3 & $100 \mathrm{~kb}$ \\
Uji Coba 4 & $200 \mathrm{~kb}$ \\
Uji Coba 5 & Kapasitas maksimal coveraudio
\end{tabular}

A. Performa Metode yang Diimplementasikan

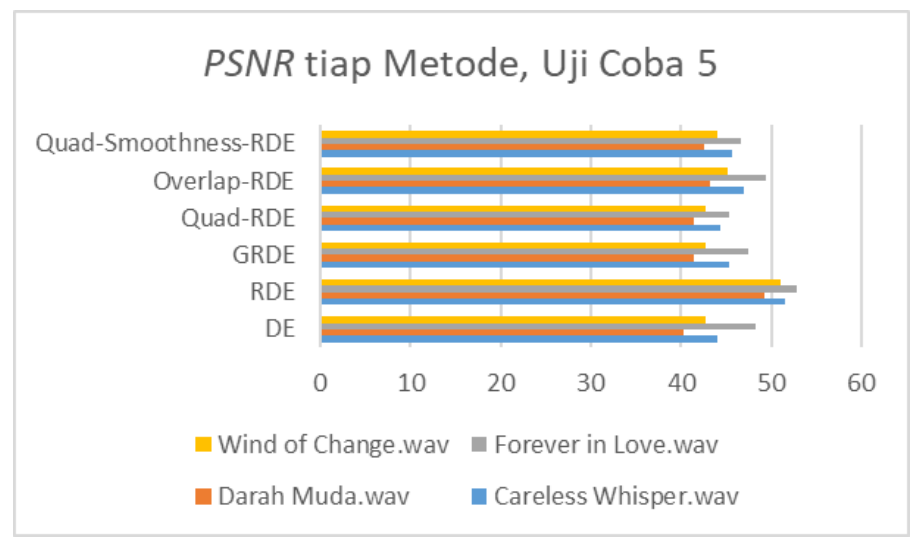

Gambar 6. Grafik PSNR tiap metode penyisipan data.

Pada Gambar 6 dapat dilihat hasil PSNR tiap metode pada Uji Coba 5. Uji Coba 5 memiliki hasil PSNR paling kecil di antara semua skenario uji coba. Metode RDE menghasilkan rata-rata nilai $P S N R$ paling besar dibandingkan metode lain.

\section{B. Kapasitas Penyisipan Data}

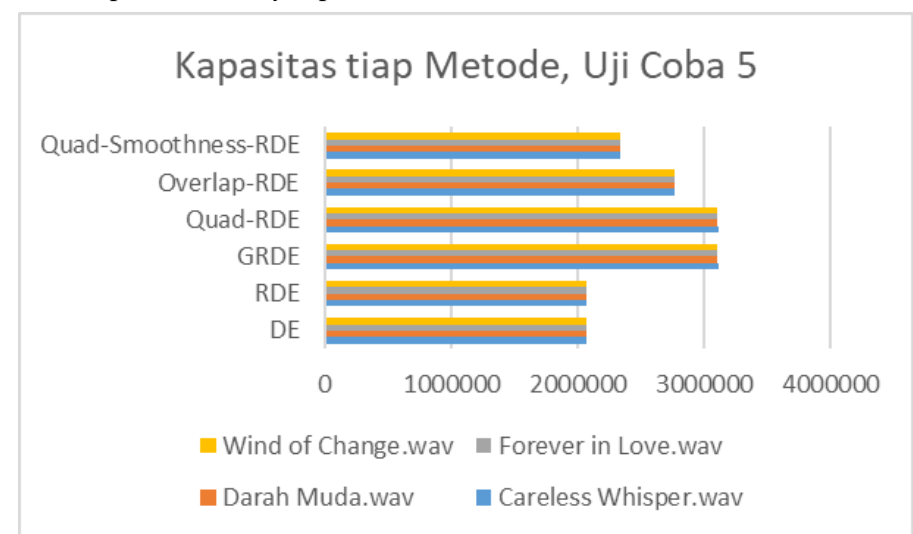

Gambar 7. Grafik kapasitas tiap metode penyisipan data.

Kapasitas dari tiap metode penyisipan didapatkan dari Uji Coba 5 yang dapat dilihat pada Gambar 7. Nilai kapasitas didapatkan dari hasil penyisipan penuh coveraudio.

\section{KESIMPULAN}

Dari skenario-skenario uji coba yang telah dilakukan didapatkan bahwa metode-metode yang diajukan dapat diimplementasikan dengan berhasil. Semua metode dapat diimplementasikan ke semua coveraudio. Pemilihan coveraudio berpengaruh pada nilai PSNR stegoaudio. Coveraudio yang memiliki grafik sampel yang halus dan perbedaan antar sampelnya sedikit dapat memiliki nilai PSNR yang besar. Panjang coveraudio tidak berpengaruh pada kapasitas penyisipan pesan tersembunyi. Kapasitas penyimpananMdippengaruhi oleh Brettokletripenyisipan pesan tersembunyi. GRDE dan Quad-RDE memiliki kapasitas penyimpanan $\mathbb{R} \notin b$ th besar dari met(ode) lainnya. Metode RDE adalah metodERRDFg memiliki hasil I PSANR yang lebih besar dari

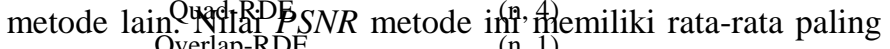
besar dibanding metode lain. Metode ${ }^{(1)}$ ini dapat menghasilkan nilai PSNR paling besar pada penyisipan pesan tersembunyi secara penuh.

\section{DAFTAR PUSTAKA}

[1] M. G. K. F. A. P. Petitcolas, R. J. Anderson, "Information hiding-a survey," in Proc. IEEE, 1999, pp. 1062-1078.

[2] M. Z. I. S. M. M. Amin, M. Salleh, S. Ibrahim, M. R. Katmin, "No Title," in 4th National Conference of Telecommunication Technology, 2003, pp. 21-25.

[3] J. Tian, "Reversible data embedding using a difference expansion," IEEE Trans. Circuits Syst, vol. 13, no. 8, pp. 890-896, 2003.

[4] T. A. dan M. Holil, "Increasing the Performance of Difference Expansion-based Steganography when Securing Medical Data," Smart Comput. Rev, vol. 4, no. 4, pp. 322-397, 2014. 